\title{
Exposure Effect on Experience and Visual Perception in Stereoscopic Visual Presentations
}

\author{
Wendy Ann Mansilla, Andrew Perkis and Touradj Ebrahimi \\ Centre for Quantifiable Quality of Service in Communication Systems (Q2S) ${ }^{1}$ \\ Norwegian University of Science and Technology (NTNU) \\ Trondheim, Norway \\ wendy.mansilla@q2s.ntnu.no, andrew@iet.ntnu.no, touradj.ebrahimi@q2s.ntnu.no
}

\begin{abstract}
The advent of new technologies in cinema, theatre and virtual reality together with increasing demands for new content, are pushing the boundaries of filmmaking and storytelling to the limits of our imaginations. The potential for 3D film to blur the line between virtual storytelling and social network gaming is not just hypothetical. These technologies now incorporate audiences and players that are actors in the virtual world themselves. They often encounter other actors they are familiar with in virtual or real-life. In social psychology, familiarity is a robust phenomenon demonstrating that just being familiar to someone causes preference and increased positive affect to them. In this paper, the role of familiarity in the visual perception and user experience is investigated. To test our findings, stereoscopic film scenarios were developed. An experiment has been conducted to see if annoyance present on a stereoscopic film content outweighs the user experience over familiarity. This paper argues that a stereoscopic 3D film technology seems to gain more from increased emotional relevance than from higher quality resolutions.
\end{abstract}

\section{Categories and Subject Descriptors}

H.1.2 [Information Systems]: Models and PrinciplesUser/Machine Systems, Human Factors; J.4 [Computer Applications]: Social and Behavioural Sciences-Psychology; 1.3.7 [Computer Graphics]: Three Dimensional Graphics and Realism.

\section{General Terms}

Experimentation, Human Factors

Permission to make digital or hard copies of part or all of this work or personal or classroom use is granted without fee provided that copies are not made or distributed for profit or commercial advantage and that copies bear this notice and the full citation on the first page. To copy otherwise, to republish, to post on servers, or to redistribute to lists, requires prior specific permission and/or a fee.

\$FH2009, 2 FWT-Oct पI, 2009, \$ WसQW* UHFH

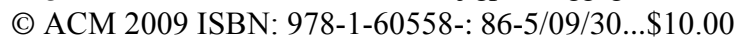

\section{Keywords}

3DTV, Stereoscopic Technology, Familiarity, Quality of Experience, Perception, Subjective Quality Test Assessment.

\section{INTRODUCTION}

One of the technologies filmmakers use to relate stories that can reach the audience both visually and viscerally is a stereoscopic $3 \mathrm{D}$ film presentation. In the academic literature, threedimensional television (3DTV) contents are said to increase the viewer's presence [17]. Along with its ability to immerse, stereoscopic presentation is expected to be the next advancement in home television. However, several challenges exist that hinder 3DTV contents from being a widespread feature in the television broadcasting arena. One among others concerns issues related to the need for wider availability of venues that are capable of broadcasting in modern 3D. However, increasing 3D venues would mean stronger demand for high quality 3D content and quality assessments to ensure an optimized user experience, and this will further emphasize the need for higher quality digital processing tools. Digital data processing includes manipulations of images for feasible and efficient human consumption. Any visual information may undergo processing to optimize it for storage or transmission. This could potentially impair the quality of the final material. For instance, compression mechanisms may introduce distortion on important parts of the visual data to save storage capacity. During transmission over a network, there is a potential possibility for content loss due to bandwidth fluctuations or congestions. And during the reception of data, losses are concealed which sometimes results in disturbing artefacts. Such distortions can result in annoyance and decreases in the viewing experience at the receiver.

Human Visual System (HVS) and perception play an important role in measuring the quality of visual presentations. In some situations, noise on the visual data could remain imperceptible or is not seen as an annoyance by the human receiver. For instance, studies of Osberger et al. [12] point that regions of high visual importance have a greater effect on overall perception of the visual quality when compared to those of lesser importance. There are several known features that affect focus of visual attention, such as contrast, size, color, brightness, orientation and motion. In

\footnotetext{
1 “Centre for Quantifiable Quality in Communication Systems, Centre of Excellence” appointed by the Research Council of Norway, funded by the Research Council, NTNU and UNINETT. http://www.q2s.ntnu.no/
} 
addition, there is also ample evidence that emotional stimuli modulate human visual perception processes. It is also known that humans are drawn to place more attention on people in a scene, in particular on their faces, eyes, mouth, and hands during a taskrelated scene exploration [14][18]. Visual attention involves more than just graphical cues, it is also linked with other factors such as emotion [e.g. [13]]. Since human visual attention is related to affect, this research attempts to investigate potential impact of the viewer's familiarity with human subjects present in a stereoscopic $3 \mathrm{D}$ content. By considering the principles of affective model of exposure effect, it is hoped that this research will shed some further light to a better understanding of mechanisms that are involved in the user experience and visual information assessment.

In this paper, we review the psychological literature related to familiarity and how it affects human visual perception. We also describe an approach to investigate the importance of emotional relevance to the user experience. In the final section, we draw some conclusions and describe the future directions of the current work.

\section{FAMILIARITY AND VISUAL PERCEPTION}

Literature has shown that familiarity impacts the human perception [e.g. [1][2][8]]. However, in the field of computer graphics and multimedia signal processing, very few related, or no existing literature to date, have investigated linkage to this phenomenon.

In psychology, one of the earliest works to affective approach in exposure effect was conducted by Fechner [5]. Later, Titchener [15] introduced the "warm glow" heuristics that occur when one feels the presence of a familiar stimulus. Affective model of exposure effect claims that an increased preference is drawn for things simply because people are familiar with them [2][19]. The more frequent the stimuli are seen by the receiver, the more attractive and likeable these stimuli appear [e.g. [11][19]]. Zajonc [19] proposed that there might be biological significance to this effect such that stimulus presented for the first time evokes feeling of uncertainty reactions which decreases with repeated exposure to stimuli.

Other research claims that ease of processing is heightened by making a stimulus familiar through prior exposure [e.g. [9]]. The initial processing of a novel stimulus requires more effort. The perceiver needs to extract several pieces of information and map representations of the stimulus in the brain. In subsequent encounters with the stimulus, processing is less complex. One experiences sense of ease when confronted with familiar stimulus, and it produces positive feelings [e.g. [6]]. One of the most interesting evidence for this claim can be found from psychophysiological experiments made by Winkielman and Cacioppo [16] showing that the processing of familiar stimuli activates the smiling muscles and has no effect on frowning muscles. Other studies also suggest that when people make judgments about the stimulus that they have encountered previously, they tend to elicit less analytical and more spontaneous judgment [6][7][10]. Thus, when two stereoscopic contents with the same characteristics of distortions, but having different stimulus, are displayed at the same time, it can be hypothesized that the viewers of stereoscopic presentation will find the familiar stimulus more enjoyable when compared to the less familiar one.
Research shows that people are excellent at identifying stimuli that are familiar to them, even from very low quality images, but are bad at recognizing, or even matching stimuli (e.g. faces) that are unfamiliar [8]. Therefore we can assume that subjects of stereoscopic presentations will find the distortions placed on a novel stimulus more annoying when compared to a familiar one.

\section{EXPERIMENT}

In this work, a subjective quality assessment procedure was used to understand the impact of familiarity in the evaluation of perceived quality in a stereoscopic presentation. Instead of measuring using a quality score, we propose to use a dual metric based on degree of annoyance. This approach has been successfully used in other works to access quality [e.g. [4]]. To further examine the impact of distortions on user experience, the degree of enjoyment was also measured.

In this section, we describe the experimental design and implementation used in this work including the three types of subjective tests that were performed: level of annoyance, level of enjoyment, and familiarity

\subsection{Procedure}

This study involved 18 subjects, ranging from 25 to 32 years of age. There were 7 female and 11 male subjects and most of them are $\mathrm{PhD}$ students. They were tested one at a time without assessment of their visual acuity or color blindness. The clips were displayed on a 50" HDTV screen, with participants sitting approximately two meters from the display. At the end of each trial, the display was put into black, and the subject was given 35 seconds to answer all subjective tests about the stimuli they have just seen.

Participants were asked not to let production-related bias such as depth of stereoscopic display or film cuts affect the rating of the annoyance and enjoyment level of the clips. The users were also asked to consider level of enjoyment based on their felt immersion (heightened focus or interest and reduced sense of time) and felt satisfaction (willingness to watch the scene) with the current quality of the material. Familiarity was subjectively measured in terms of mere exposure to (strength of frequency they have seen or known) the actors. The participants were also asked to verify the name or identity of the actors. In addition, the users were informed that it is important for them not to spend too much time thinking about responses, and that instead, initial impressions are more valuable answers.

\subsection{Stimuli}

Subjects viewed a total of 19 pairs of stereoscopic video clips (participant sees two sets of sequences shown on the left and right part of the display) running at 20 to 24 seconds each. The distortion used in the experiments is characterized by a blocking artefacts typically introduced in an MPEG coded video during transmission or compression. The distortions introduced on every clip have equal characteristics (see Figure 1). All video clips were played only once during the experiment. The materials were encoded using H.264/AVC, in HDTV format size of 1920 X 1080 pixels.

In each test case two actors were shown to the viewer in parallel, both performing similar sequence of actions or motion, such as dancing, walking or waving hands. Majority of the pair of sequences during the formal testing contains one of the actors 
with an officemate of the subject (12 video clips), representing a supposedly familiar object, and another one (representing supposedly less familiar or unfamiliar stimulus) is a celebrity or known fictional actor (5 video clips) or unknown fictional character ( 7 video clips) and 2 pairs of clips containing unknown persons. Sequences during the demonstration trials contain mostly fictional characters and unknown persons. Most actors were shown only once in each trial otherwise, there are three clips showing previous actors playing a different role.
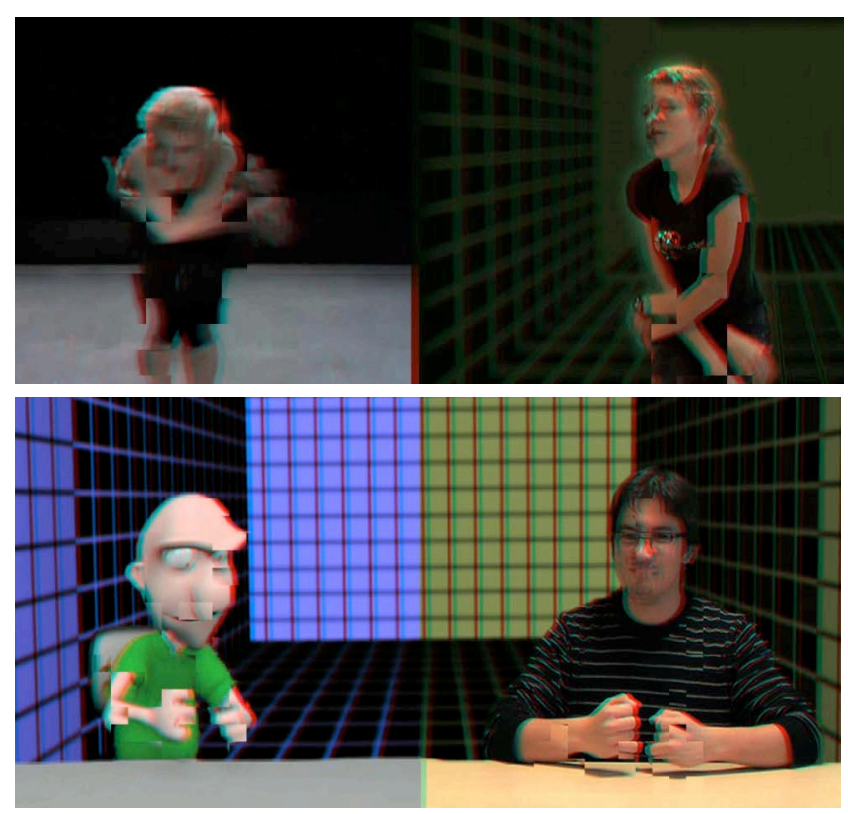

Figure 1. Snapshots of clips used in experiments (anaglyph glasses are needed to view these images properly).

\subsection{Data Analysis}

In this study, the independent variable is the familiarity of the participants to the clip (measured on a five-point scale and the name or identity of the actor seen on each clip). The dependent variables were two elements in the quality of perception: level of annoyance and level of enjoyment (both were measured on a fivepoint scale, normalized between 0 and 1). Data was analyzed with the Statistical Package for the Social Sciences (SPSS), a t-test was extracted to analyze the differences of results between familiar and unfamiliar character in a stereoscopic content. In addition, An ANalysis Of VAriance (ANOVA) was employed to test the significant differences between level of annoyance and level of enjoyment.

Based on ITU-T recommendation, the first five trials in experiments are disregarded. The subjective ratings on familiarity gathered from the participants were used as a basis to divide the materials into two categories, resulting to seven video sequences that are classified as containing familiar and unfamiliar actors and another set of five sequences containing two familiar actors. Two clips were classified to contain two actors that were completely unfamiliar to the subjects are disregarded. Two outliers were identified and are also disregarded from the current experiment.

\section{DISCUSSION OF RESULTS}

Our analysis has shown that when the participants are familiar to the two actors on the stereoscopic clips shown, the difference in the annoyance rating is significantly low at $0.625 \mathrm{vs} .0 .623$ (mean difference of upper and lower boundaries at $95 \%$ confidence interval) for the annoyance rating (see Figure 2). However, the subjects rated more emotionally relevant clip (i.e. officemate) as more enjoyable (than the familiar celebrity) at mean difference of 0.648 vs. 0.484 , respectively (at significance level of $p<0.05$ ).

In the video contents where one is unfamiliar (a fictional character) and the other is familiar (i.e. officemate), subjects tend to rate the unfamiliar slightly more annoying than the ones with familiar content (at mean difference of 0.651 vs. 0.516 , see Figure $3)$. Subject also rated familiar stimulus more enjoyable than the later (at mean difference of 0.605 vs. $0.347, \mathrm{p}<0.05$ ).

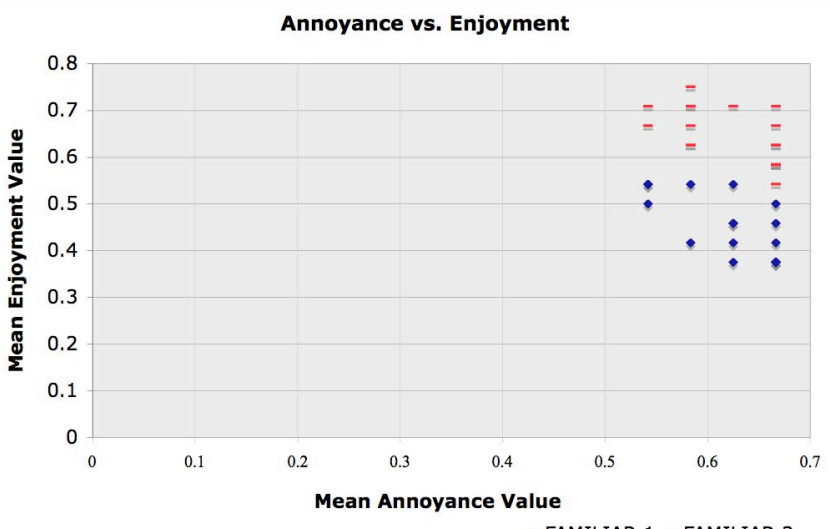

- FAMILIAR 1 - FAMILIAR 2

Figure 2. Level of annoyance and enjoyment comparison when the subjects are familiar to the two actors of stereoscopic presentation shown.

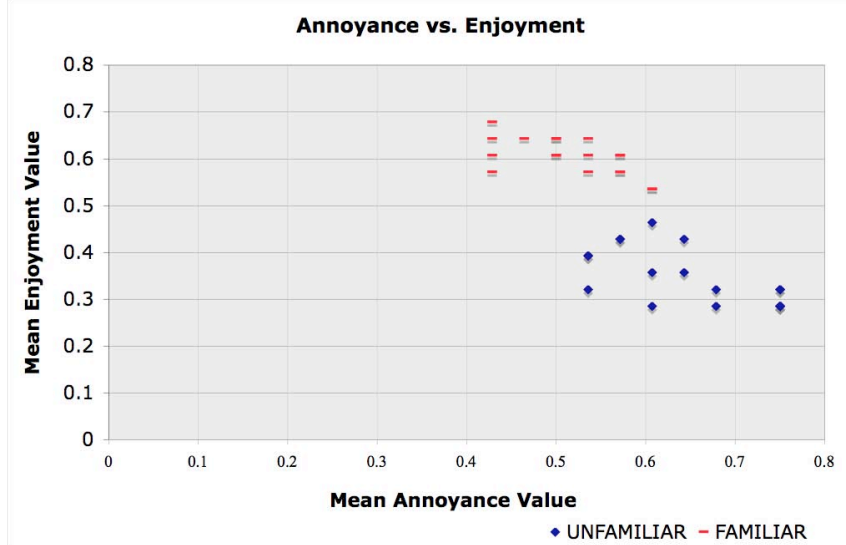

Figure 3. Level of annoyance and enjoyment comparison when the subjects are familiar to one of the actors and unfamiliar to the other in the stereoscopic presentation shown.

There were two subjects in the experiment who were also actors of the clips. None of them saw the clips before. It is observed that 
even though the subjects laugh at their own performance, they reported lower or equal level of enjoyment with the corresponding clip and also reported more annoyance to distortions in the clip. Perhaps, one interesting element that can be further investigated is to introduce a finer grained measurement to the level of familiarity of the subject by producing more customised contents that contains objects that are even more emotionally relevant to the user (e.g. self-representation, family, favourite fictional character), and then studying how these factors affect visual perception and emotional processes.

In slightly different domain, these results seem to be in line with Cutting's [3] observation using still images of reproduced paintings. He observed that what governs judgment in preference is not the quality of the visual material or reproduction but how often the images are seen before.

\section{CONCLUSION AND FUTURE WORK}

In this paper, we have presented an approach to investigate the importance of increasing user's personalisation in creating new multimedia presentations. We provided an analysis that has highlighted that familiarity influences the user's enjoyment more than the distortions present on the stereoscopic clips. We argue that a stereoscopic 3D film technology seems to gain more from increased emotional relevance than from higher technical quality.

The results of this study show that when the participants are both familiar to the characters on the contents shown, the mean difference in the annoyance rating is significantly low. However, subjects rated the more emotionally relevant content as more enjoyable. In contents where one is unfamiliar and the other is familiar, subjects tend to rate the unfamiliar more annoying than the ones with familiar content. Consistent to the previous finding, subject rated familiar stimulus more enjoyable than the latter.

As part of future work, we would like to extend the current work in designing a model of an adaptive system that considers the affective relevance and increased personalisation of the users. We are currently working on a streamed stereoscopic live theatre performance project to further quantify the relationship between real actors and avatars with viewer's visual perception and affective processes.

\section{REFERENCES}

[1] Arkes, H.R., Hackett C., \& Boehm L. (1989). The generality of the relation between familiarity and judged validity, Journal of Behavioral Decision Making 2, pp. 8194.

[2] Bornstein, R.F. (1989). Exposure and affect: Overview and meta-analysis of research, 1968-1987, Psychological Bulletin 106 pp. 265-289.

[3] Cutting, J. E. (2003). Gustave Caülebotte, French Impressionism, and mere exposure. Psychonomic Bulletin \& Review, 10, pp. 319-343.

[4] Drelie Gelasca, E., Ebrahimi, T., Farias, M., Carli, M., \& Mitra, S. (2004) Annoyance of Spatio-Temporal Artifacts in Segmentation Quality Assessment. In Proceedings of the International Conference on Image Processing, International, ICIP'04, IEEE Vol. 1, pp. 345-348.

[5] Fechner, Gustav T. (1876). Vorschule der Ästhetik.
[6] Garcia-Marques, T., \& Mackie, D. M. (2000). The positive feeling of familiarity: Mood as an information processing regulation mechanism. In: J. Forgas and H. Bless, Editors, The message within: The role of subjective experiences in social cognition and behavior, Psychological Press, Philadelphia, pp. 240-261.

[7] Garcia-Marques, T., \& Mackie, D. M. (2001). The feeling of familiarity as a regulator of persuasive processing. Social Cognition, 19, pp. 9-34.

[8] Hancock, P. J. B., Bruce, V., \& Burton, A. M. (2000). Recognition of unfamiliar faces. Trends in Cognitive Science, 4, pp. 330-337.

[9] Jacoby, L. L., Kelley, C., Brown, J., \& Jasechko, J. (1989). Becoming famous overnight: Limits on the ability to avoid conscious influences of the past. Journal of Personality and Social Psychology, 56, pp. $326-338$.

[10] Johnston W.A., \& Hawley K.J. (1994). Perceptual inhibition of expected inputs: The key that opens closed minds, Psychonomic Bulletin and Review 1, pp. 56-72.

[11] Moreland, R.L., \& Zajonc, R.B. (1982). Exposure effects in person perception, Journal of Experimental Social Psychology 18, pp. 395-415.

[12] Osberger W., Maeder, A.J. \& N. W. Bergmann N.W. (1998) A technique for image quality assessment based on a human visual system model. To appear in 9th European Signal Processing Conference (EUSIPCO-98).

[13] Rosler, A., Ulrich, C., Billino, J., Sterzer, P., Weidauer, S., Bernhardt, T., Steinmetz, H., Frolich, L., \& A. Kleinschmidt (2005). 'Effects of arousing emotional scenes on the distribution of visuospatial attention: Changes with aging and early subcortical vascular dementia.' Journal of the Neurological Sciences, pp. 229230, 109-116.

[14] Senders, J.W. (1997). Distribution of attention in static and Dynamic Displays. In Proceedings of the SPIE - Human Vision and Electronic Imaging II, Vol. 3016, Bernice E. Rogowitz; Thrasyvoulos N. Pappas; Eds. pp. 186-194.

[15] Titchener, E. B. (1910). A Text Book of Psychology. New York: Macmillan.

[16] Winkielman, P., \& Cacioppo, J. T. (2001). Mind at ease puts a smile on the face: Psychophysiological evidence that processing facilitation elicits positive affect. Journal of Personality and Social Psychology, 81, pp. 989-1000.

[17] Yano, S., \& Yuyama I. (1991). Stereoscopic HDTV: Experimental system and psychological effects, Journal of the SMPTE, Vol. 100, pp. 14-18.

[18] Yarbus, A.L. (1967) Eye Movements and Vision. Premium Press, New York NY.

[19] Zajonc, R.B. (1968) Attitudinal effects of mere exposure, Journal of Personality and Social Psychology 9, pp. 1-27. 